\title{
Scientific Evidence about the Assistance Provided to the Newborn with Meconium Elimination: Integrative Literature Review
}

\author{
Marília Cordeiro de Sousa1, Lívia Roberta Rodrigues Conceição1, Marcela de Andrade Silvestre ${ }^{1}$, \\ Lays de Souza Silva1, Camila de Pina Soares Sudário', Renata Calciolari Rossi²,

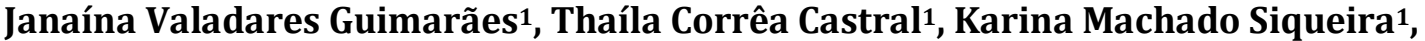 \\ Pedro Teixeira Meireles ${ }^{3}$, Bruno Belmonte Martineli Gomes ${ }^{4}$, George Kemil Abdalla5, \\ Douglas Reis Abdalla5*, Ana Karina Marques Salge ${ }^{1}$
}

${ }^{1}$ Faculty of Nursing, Federal University of Goiás, Goiânia, Brazil

${ }^{2}$ Western Paraná State University, Cascavel, Brazil

${ }^{3}$ Medicine Course, University of Uberaba, Uberaba, Brazil

${ }^{4}$ Biomedicine, University of São Paulo, Ribeirão Preto, Brazil

${ }^{5}$ Health Sciences, Faculty of Human Talents, Uberaba, Brazil

Email: ^drabdalla@facthus.edu.br

How to cite this paper: de Sousa, M.C., Conceição, L.R.R., de Andrade Silvestre, M., de Souza Silva, L., de Pina Soares Sudário, C., Rossi, R.C., Guimarães, J.V., Castral, T.C., Siqueira, K.M., Meireles, P.T., Gomes, B.B.M., Abdalla, G.K., Abdall, D.R. and Salge, A.K.M. (2020) Scientific Evidence about the Assistance Provided to the Newborn with Meconium Elimination: Integrative Literature Review. Open Journal of Obstetrics and Gynecology, 10, 504-515. https://doi.org/10.4236/ojog.2020.1040045

Received: March 2, 2020

Accepted: April 102020

Published: April 13, 2020

Copyright $\odot 2020$ by author(s) and Scientific Research Publishing Inc. This work is licensed under the Creative Commons Attribution International License (CC BY 4.0).

http://creativecommons.org/licenses/by/4.0/

\begin{abstract}
The Meconial Aspiration Syndrome (MAS) is a complication caused by the presence of meconium amniotic fluid with consequent aspiration, being responsible for important rates of perinatal morbidity and mortality. This study aims to analyze the bibliographical production on newborn care with meconium elimination in the delivery room. It was a literature integrative review electronically based. Most of the studies referred to tracheal intubation and exogenous surfactant ministration as main care methods. The Meconium Aspiration Syndrome is presented as main theme. It is understood that health care professionals must develop knowledge, skills and actions, showing conduct based on scientific, critical and reflexive knowledge with purposeful interventions directed to the patient's needs.
\end{abstract}

\section{Keywords}

Perinatal Care, Meconium Aspiration Syndrome, Newborn

\section{Introduction}

Meconium is the newborn's first evacuation that can be recognized for his color dark green or black and the lack of odor [1]. It consists of gastrointestinal secre- 
tions, bile acids, mucus, pancreatic juice, cellular waste, amniotic fluid, caseous vernix, lanugo and swallowed blood [2]. Furthermore, it is believed that its formation begins around the 12th week of gestation, when the fetus begins to swallow the amniotic fluid [1].

The concentration of meconium in the amniotic fluid depends on the amount of amniotic fluid present in the amniotic cavity and how much meconium has been eliminated [3]. In cases of hypoxia or presence of perinatal infection, a probable cause may be due to the elimination of intrauterine meconium, being dispersed in the amniotic fluid in greater concentration and quantity, favoring aspiration by the fetus [4].

This aspiration of meconium amniotic fluid is facilitated if the fetus presents forced respiratory movements, causing airway obstruction, interference with gas exchange and severe breathing difficulties, which may develop meconium aspiration syndrome. In the same sense, if there is elimination or thickening of meconium during labor, the chances of the newborn developing complications are doubled [4] [5].

The Meconial Aspiration Syndrome (MAS) is a complication caused by the presence of meconium amniotic fluid with consequent aspiration, being responsible for important rates of perinatal morbidity and mortality [6]. The diagnosis is made by a history of meconium amniotic fluid, presence of meconium in the newborn's trachea and compatible radiological alteration, with areas of coarse granular atelectasis alternating with areas of hyperinflation in the pulmonary fields, and areas of lobar or multilobar consolidation may also appear, interstitial emphysema, pneumothorax and/or pneumomediastinum [7].

There are some maternal antecedents that are frequently observed in association with Meconial Aspiration Syndrome, such as: arterial hypertension, chronic cardiovascular or pulmonary disease, acute hypotension, placenta previa, premature displacement of the placenta, presence of prolapses, circular and cord nodes [8].

The Meconial Aspiration Syndrome causes mechanical, chemical and inflammatory responses that interfere with the passage from the intrauterine to the extrauterine environment, leading the newborn to develop complications [9]. If there are no complications of meconium aspiration, such as barotrauma and/or pulmonary hypertension, meconium is absorbed gradually with an improvement in the condition of 5 to 7 days [7].

In the development of pregnancy, $10 \%$ to $20 \%$ of cases can be observed the presence of meconium amniotic fluid and $1 \%$ to $2 \%$ of these newborns will present MAS [7]. In industrialized countries, the occurrence of birth with the presence of meconium amniotic fluid corresponds to $8 \%$ to $25 \%$ of births after the 34 th week of pregnancy and MAS occurs in about $1 \%$ to $3 \%$ of newborns [10].

The conditions of pregnancy, childbirth and especially the quality of care that is provided in the delivery room, strongly imply situations of greater or lesser 
severity in cases of MAS. The newborns with MAS needs intensive care, with a specialized team and advanced equipment, being referred to a Neonatal Intensive Care Unit (NICU) [4]. Technological advances and knowledge about therapeutic modalities have reduced the rate of morbidity and mortality, however, further studies on the topic are still needed [11].

Thus, the aim of the present study was to analyze the bibliographic production on assistance provided to the newborn with meconium elimination in the delivery room through an integrative literature review.

\section{Methods}

To carry out the study, it was decided to conduct an integrative literature review. Integrative analysis is a specific review method that enables the analysis and synthesis of knowledge about a particular phenomenon or health problem. The method allows the inclusion of several methodologies and has a strong influence on evidence-based nursing practices [12].

For this, the present study was carried out in 6 methodological stages. The first stage consisted of identifying the problem, the search engine presented and the descriptors or keywords described. In the second stage, the inclusion and exclusion criteria of the articles were established for a sample composition. The third stage consisted of an exploratory reading of the titles and abstracts of the articles for pre-selection. The fourth stage consisted of the analytical reading of the articles to compile, analyze and categorize the information. In the fifth stage, the results were interpreted. And, in the last stage, the results were synthesized and presented, which permeate the guiding question (Figure 1) [13].

Then, the selected articles were characterized based on the identification of the study (title, authors, journal), year of publication, database, type of study, objectives and main results (Chart 1 ).

The search strategy in health database and Decs/MeSH terms:

LILACS "meconium aspiration syndrome" [Words] and "newborn" [Words] and "perinatal care" [Words]; Scielo library “meconium” [Subject] and “newborn” [Subject]; PubMed databases ([meconium aspiration syndrome [MeSH Terms]), newborn [MeSH Terms]) and perinatal care [MeSH Terms]

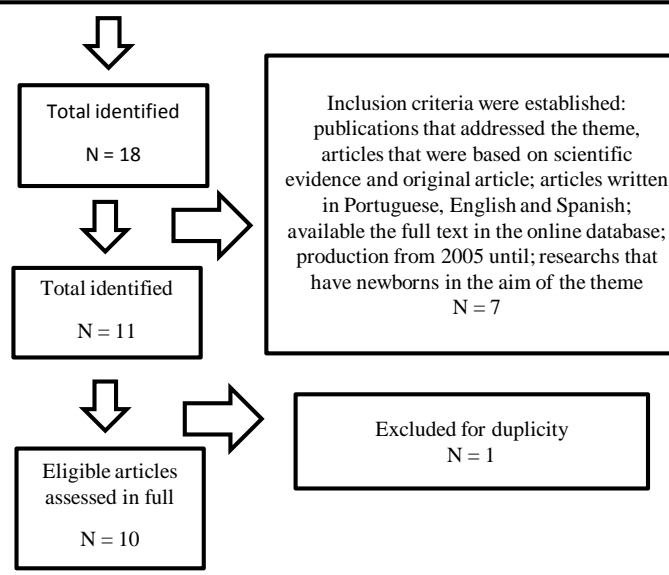

Figure 1. Flowchart of selection of publications. 
Chart 1. Distribution of studies regarding assistance to newborns with meconium elimination in the delivery room according to study identification, year of publication, type of study, objectives and main results.

\begin{tabular}{|c|c|c|c|c|}
\hline $\begin{array}{l}\text { Study identification } \\
\text { (title, authors, journal) }\end{array}$ & $\begin{array}{l}\text { Year of Data } \\
\text { publication bases }\end{array}$ & Study type & Objectives & Principal results \\
\hline
\end{tabular}

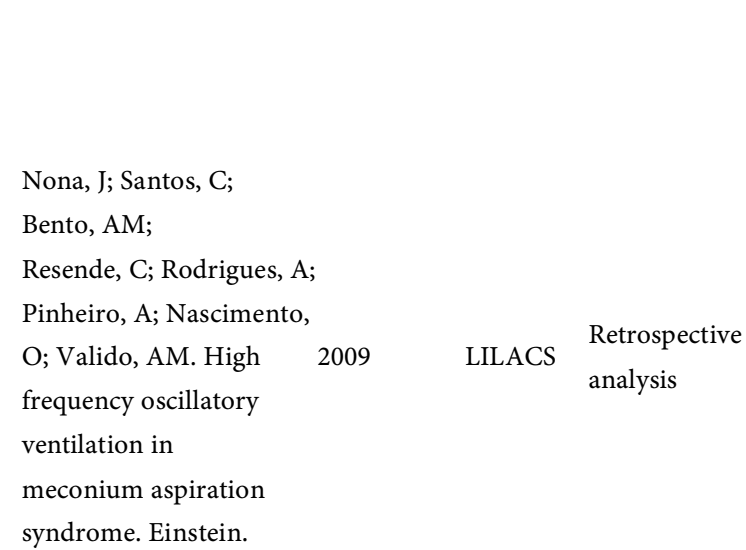

Daripa M, Caldas EMG,

Flores LPO, Waldvogel

BC, Guinsburg R,

\section{Almeida MFB. Asfixia}

perinatal associada à

mortalidade neonatal

precoce: estudo

populacional dos óbitos

evitáveis. Rev. paul.

pediatr.

Bhutani, VK. Developing

a systems approach to

prevent meconium

aspiration

syndrome: lessons

learned from

multinational studies.

Journal of Perinatology
Evaluate and compare the performance and morbidity associated with meconium aspiration syndrome

in newborns in the maternity ward or admitted from outside hospitalized in our Neonatal Intensive Care Unit and in high-frequency oscillatory ventilation

- The therapy consists of the administration of surfactant in 22 newborns (13 admitted outside), nitric oxide in 12 (seven admitted outside) and magnesium sulfate in 4 ( 3 admitted outside).

- The average ventilation time was 6 days ( 4.5 days for those born in the maternity ward and 10 days for those admitted outside), and the median time of oxygen supplementation was 10 days ( 4.5 days for those born in the maternity ward and 15 days for those admitted from outside).

- The average length of stay was 13 days (11 days for those born in the maternity ward and 16 days for those admitted outside). A newborn admitted from outside died. The ventilatory strategy used, did not observe statistically significant differences between the two groups of newborns, except for the time of need for supplementation with oxygen, which was higher in the group of newborns admitted outside.

Compare the epidemiological profile of preventable early neonatal deaths associated with perinatal asphyxia according to the region where the death occurred in the State of São Paulo.

- Between 2001 and 2003, 1.71 deaths per 1000 live births were associated with perinatal asphyxia, corresponding to $22 \%$ of early neonatal deaths. - Of the 2873 preventable deaths, 761 (27\%) occurred in São Paulo, capital; 640 (22\%), in the capital's metropolitan region; and 1472 (51\%), in the interior of the state.

- Meconium aspiration syndrome was present in $18 \%$ of deaths.

- Treatment options continuous airway pressure (CPAP), conventional ventilation management, has been replaced by synchronized intermittent mandatory Evaluate the evidences about the crucial steps necessary in the prevention of meconium aspiration syndrome, concomitant neonatal death and illness in the perinatal context of the diversified health services. ventilation (SIMV), high frequency oscillatory ventilation (HFOV), surfactant, inhaled nitric oxide (iNO), and oxygenation by extracorporeal membrane (ECMO). Exogenous surfactant therapy has been successfully implemented. However, these innovative interventions are expensive, require a sophisticated infrastructure and are not universally accessible. - Over the period of 6 years (1995-2000) the birth of babies in an urban perinatal center (Philadelphia, USA) was analyzed. $14.5 \%(3370 / 23,175)$ births were of babies with suspected MAS and $4.6 \%$ of them were diagnosed with MAS. Overall, $26 \%$ of babies (40/155) with MAS required necessary ventilatory support; of these, only $20 \%(8 / 40)$ needed innovative ventilatory support. None died or needed ECMO. 


\section{Continued}

Colvero, MO;

Colvero, AP;

Fiori, RM;

Garcia, PC.

Novas opções

terapêuticas na

2006

síndrome de

aspiração de mecônio.

Rev. Bras. Saúde Matern.

Infant.
Review the literature on meconium aspiration syndrome (MAS), focusing on clinical, pathophysiological aspects and the therapeutic approach, with

emphasis on the use of surfactant and bronchoalveolar lavage.

To evaluate the effect

eyr GJ, Xu, H.

Amnioinfusion for in labour. Cochran

Database

of Systematic Reviews meconium fluid on the perinatal outcome.
Hofer N, Jank K, Resch E, Urlesberger B, Reiterer F, Resch B. Meconium Aspiration Syndrome-a 21-years' Experience from a Tertiary Care

Center and Analysis of

Risk Factors for

Predicting Disease Severity. Klin Padiatr.
PubMed Retrospective analysis

Lin HC; Wu SY; Wu, JM;

\section{Yeh, T. Meconium}

aspiration syndrome: experiences in Taiwan. 2008 [15] PubMed

Journal of

Perinatology

- An ECMO is one of the main indications of the mas tomb, but it is extremely expensive, invasive and is not available in our country. It is recommended that newborns (NB) expose a mechanism that is aspirated by the wall suction system, and the tracheal intubator is indicated in cases where the NB suffering from respiratory depression, or the use of CPAP should be considered in diseases lighter, with careful monitoring of complications.

- It is controversial or use of antibiotic therapy, being commonly recommended in view of the severity of the condition and infectious process. The replacement and bronchoalveolar lavage with surfactant are being studied, showing themselves as effective measures in the prevention of breast cancer.

- In units with standard peripartum surveillance, the evidence does not support the benefits in practice regarding the use of amnioinfusion for meconium amniotic fluid, since it is an invasive procedure and its benefits have not been clearly identified in clinical studies. It is concluded that there is a need to conduct more research.

of amnioinfusion for - In units with limited peripartum surveillance, 2

studies show significant improvements with the simplified amnioinfusion technique in pregnant women with oligodramnios. It is concluded that there is a need for further studies to determine the benefits of amnioinfusion in the sense of being limited only to women with oligodramnium pregnancies, and the possible risks for the mother.

- The study was carried out at the tertiary care service affiliated with the university, researching newborns

Describe the course of (NBs) diagnosed with MAS between 1990 and 2010, perinatal factors in neonates with meconium aspiration syndrome (MAS) of 1990-2010 and determine risk factors for disease severity. totaling a sample of $8000 \mathrm{NBs}, 2600$ of whom were born in that service.

- 205 NBs were diagnosed with MAS. Among the main risk factors for MAS are: neonatal asphyxia, post-term newborns, acute tocolysis, fetal distress and severe delivery.

- The study concludes that there was an apparent reduction in the incidence of MAS that can be explained by a better knowledge of risk factors and advances in obstetric practices.

- The incidence of MAS has decreased in Taiwan in the past decade, as the population has access to better health and care services.

Review and summarize previous studies on - Increased mortality is associated with children with MAS who required resuscitation maneuvers, meconium aspiration syndrome (MAS) in two tertiary neonatal centers in Taiwan. asphyxiation at birth and newborns who developed pulmonary hypertension and pneumothorax.

- The use of dexamethasone reduced the inflammatory process and improved cardiopulmonary perfusion, not preventing the development of pulmonary hypertension, but its use is still being studied. 
Steven M; Donn MD;

Dalton JMD. Surfactant

Replacement Therapy in

the Neonate:

2009

Beyond Respiratory

Distress Syndrome.

RESPIRATORY CARE

Fraser WD, Hofmeyr J,

Lede R, Faron G,

Alexander S, Goffinet F,

Ohlsson A, Goulet C,

Turcot-Lemay L,

Prendiville W, Marcoux

$S$, Laperrière L, Roy C,

Petrou S, Xu HR, Wei B.

Amnioinfusion for the

prevention of the

meconium aspiration

syndrome. N Engl J Med

Meritano J, Abrahan MS,

Pietro SVD, Fernández

V, Gerez, G. Síndrome de

dificultad respiratoria

asociado a líquido

amniótico meconial en

recién nacidos de

término y postérmino:

incidencia, factores de

riesgos y

morbimortalidad. Rev.

Hosp. Mat. Inf.

- Meconium is a mixture of gastrointestinal secretions, epithelial cells and other substances that appear in the amniotic fluid, many of them, mainly bile salts, can inactivate the surfactant, in addition to having a toxic effect on the lung, causing chemical pneumonia, among others.

To evaluate the effects - The use of surfactant is well known in respiratory of surfactant distress syndrome, however, in a randomized controlled replacement therapy onstudy in 1996, it was observed that the use of surfactant

PubMed

Retrospective analysis

two diseases:

syndrome (MAS) and length of stay. Thus, as the lung washing technique with respiratory distress syndrome.

surfactant has become another alternative.

- There is still much to learn about pharmacology and clinical trial
PubMed Controlled

Determine whether amnioinfusion reduces the risk of outcome of perinatal, moderate or severe death in meconium aspiration syndrome (MAS), or both. And evaluate the effect of the intervention on the risk of cesarean section, other important neonatal indicators and maternal diseases.

To estimate the incidence of meconium amniotic fluid (MAL) and the relationship between

Transversional respiratory distress

PubMed observational syndrome, the study pharmacokinetics of surfactants; however, studies propose that surfactant replacement therapy can overcome inactivation and production, emphasizing the need to observe long-term results, in addition to measures to reduce short-term effects and the need for extracorporeal membrane oxygenation (ECMO).

- A total of 1975 women were randomized, 986 for the amnioinfusion group and 989 for the control group. Perinatal death, moderate or severe meconium aspiration syndrome, or both, occurred in 44 children of women belonging to the amnioinfusion group and 35

children of women belonging to the control group. There were 10 perinatal deaths, 5 in each group. - The cesarean section rate was $31.8 \%$ in the amnioinfusion group and in the control group the rate was $29 \%$. Some serious complications, such as maternal peripartum fever, uterine rupture, pre-delivery hemorrhage, hysterectomy and disseminated intravascular coagulation did not differ significantly between groups.

- In women in labor and with thick amniotic fluid, the amnioinfusion procedure did not reduce the risk of moderate or severe MAS, perinatal death or other neonatal or maternal disorders, therefore, it should not be recommended for the prevention of meconium aspiration syndrome.

- Clinical histories of newborns were selected from 2007 to 2008 , the sample had 1150 with thick MAL and 2300 with clear MAL. The populations had similar characteristics, such as a higher incidence of cesarean section and primiparity in the thick MAL group, increasing with gestational age.

- Refers to follow the recommendations of the Academy American Pediatrics and Cochrane reviews, which association with risk suggest aspirating the depressed newborn only once, factors and morbidity using surfactant and mechanical ventilation to decrease in term and post-term complications and mortality.

newborns at Maternity - The risk of developing respiratory distress syndrome Hospital "Ramón Sardá” is 2.5 times higher in newborns with thick MAL compared to clear MAL, with a greater tendency to escape air, mortality and lower Apgar score. 
The selected articles were characterized based on the identification of the study (title, authors, journal), year of publication, database, type of study, objectives and main results (Chart 1 ).

An exploratory reading and selection of the material was carried out, followed by an analytical reading, through the reading of the selected works, which made it possible to organize the ideas in order of importance and later fixation. After the analytical reading, the interpretative reading started, which dealt with the comment made by linking the data obtained, emphasizing the main ideas. Next, the data presented were submitted to content analysis and a synthesis of knowledge was carried out for the construction of the article.

\section{Results and Discussion}

\section{Characterization of the studies}

The sample consisted of 10 articles, two of them were in Portuguese, one was in Spanish and 7 in English. The works were published from 2005 to 2015, one in a periodical in England, one in a periodical in Germany, one in a periodical in Argentina, three in Brazilian periodicals and four in American periodicals (Chart 1).

Regarding the research design, six studies were retrospective studies, a cohort study work, a systematic review work, a controlled clinical trial work and one work was an observational and cross-sectional study. The clinical trial was conducted with women and newborns and the cohort study was composed of newborns.

Risk factors, maternal variables and neonatal variables for the prevention of meconium aspiration syndrome

The maternal variables for the presence of meconium in the amniotic fluid include: arterial hypertension, pre-eclampsia/eclampsia, diabetes mellitus, smoking, cardiovascular diseases, chronic respiratory diseases, post-term pregnancy and oligodramnios, fewer prenatal consultations. Among neonatal variables, intrauterine growth restriction (IUGR), cardiac congenital anomalies, male, the lowest Apgar score [11] [16] stand out. Neonatal asphyxia, acute tocolysis, fetal distress and complicated delivery are still among the main risk factors for the development of MAS [17].

Thus, the incidence of MAS varies from population to population and from one country to another [18] [19]. And the apparent reduction in the incidence of this pathology in some countries is due to a greater knowledge of risk factors and advances in obstetric practices [17].

Assistance provided to the newborn with meconium elimination in the delivery room

Neonatal management has changed based on new studies carried out in recent years [11]. Aspiration at birth, before leaving the shoulders, followed by tracheal intubation (TI) and tracheal aspiration of newborns with MAS, has been a routine procedure for the past 25 years. However, multicenter studies indicate the discontinuation of the practice of secretion aspiration in the intrapartum period, 
as this procedure does not decrease the frequency of MAS [20] [21]. In addition, a prospective, randomized and controlled study, conducted by Halliday and Sweet [22], concluded that TI and aspiration of the NB with vigorous MAS did not show a reduction in the incidence of MAS compared to the usual assistance recommended for transport procedures in depressed newborns. A Cochrane review in 2007 came to the same conclusion, using the recommendations of the American Academy of Pediatrics and the American Heart Association (AHA) [22].

According to the AHA if there is MAS fluid or thick, the professional should not perform aspiration of the airways, since this procedure does not reduce the incidence of MAS, the need for mechanical ventilation in newborns who develop aspiration pneumonia, nor the oxygenation time or even hospitalization. Therefore, the assistance of the professional through the presence of red MAS will depend on vitality at the time of birth. If the newborn presents, at birth, regular and rhythmic respiratory movements, good muscle tone and heart rate (HR) greater than 100 beats per minute (bpm), he/she should be referred to the resuscitation table, placed under a radiant heat source, and must have the head positioned with a slight extension of the neck, and be aspirated, if there is an excess of secretions in the mouth and nose with a tracheal tube number 10, then dried, with subsequent disregard of the wet fields. After these procedures, check the head position again, assessing breathing and HR. If the evaluation shows a normal result, the NB will receive routine care in the delivery room [23].

In the other hand, if the NB with fluid or thick MAS, at birth, does not have a regular respiratory rhythm and/or has a flaccid muscle tone and/or HR below $100 \mathrm{bpm}$, the professional should remove the residual meconium from the hypopharynx and the trachea with direct visualization, under a radiant heat source. Tracheal aspiration will be performed by means of a tracheal cannula connected to a device for meconium aspiration and vacuum aspiration, with a maximum pressure of 100 millimeters of Mercury $(\mathrm{mmHg})$, aspirating excess meconium only once; if the newborn remains with HR below $100 \mathrm{bpm}$, irregular breathing or apnea, start positive pressure ventilation (PPV). It is also recommended that PPV should only be performed after the removal of meconium from the airways and gastric aspiration, with this sequence the aim is to reduce the risk of vomiting and consequently aspiration [22] [24].

Various types of mechanical ventilation have been discussed at MAS. Continuous positive airway pressure (CPAP) has been described as beneficial, possibly because it controls atelectasis, stabilizing the collapsing terminal airways, however, it should be used with caution in pulmonary hypertension, and must monitor complications frequently [25].

According to Walsh and Faranoff [16] the advancement of technology and knowledge in assisting MAS contributes to the reduction of mortality rates, citing the use of surfactant and extra-corporeal circulation (ECMO) as new techniques.

The obstruction of the airways by meconium can increase the resistance and 
the deficiency of surfactant, as well as changes in the lung parenchyma may require the use of ventilatory support, supplemental oxygen, so to break this cycle there is an indication of the use of exogenous surfactant. In this sense, two approaches have been discussed: the first is the replacement of surfactant and the second is the washing with surfactant. In the first approach, exogenous surfactant is administered via an endotracheal tube, usually at the same dose as indicated for Hyaline Membrane Syndrome (HMS), using standard surfactant preparations [26].

The surfactant has proven benefits, such as improved oxygenation, consequently reducing the need for mechanical ventilation and hospital stay, in addition to reducing respiratory complications and mortality in newborns. Several diseases that affect the term newborn are associated with the reduction or inhibition of the surfactant, especially MAS. The use of surfactant has a possible detergent effect on meconium [8].

Halliday et al. [22] was one of the first scholars to discuss the use of surfactants at MAS. In its retrospective review study it included 54 newborns with MAS who received surfactant therapy on average 14 hours after birth, with varying doses used. The results showed that one third of the NBs needed a repeat dose, $18 \%$ showed a significant improvement in gas exchange, $44 \%$ showed little or no response, plus only two NBs needed extracorporeal membrane oxygenation therapy. ECMO has been indicated when failures in ventilatory assistance occur with different ventilation strategies, however, it is an expensive treatment that requires an adequate infrastructure, limiting its use in certain health centers [8].

The second approach, still according to studies by Steven, Donn and Dalton [26] is the use of bronchoalveolar lavage with surfactant, which aims to remove the harmful substances that are present in the airways, among them the meconium itself, neutrophils, protein exudate and mediators inflammatory. Colvero and Garcia [8] argue that due to the conflicting results between the use of surfactant and that of bronchoalveolar lavage with surfactant in MAS, it would be important to carry out further studies to assess whether there are benefits in its use, as well as to define the ideal dose and the way to be administered. They still argue that the use of antibiotic therapy is controversial, however these drugs are usually recommended due to the severity of the condition, as well as the difficulty of excluding infectious processes, since meconium has great potential for colonization by germs, mainly by gram-negative.

Amnioinfusion or transcervical infusion of saline into the amniotic cavity is a procedure that has been proposed to reduce the risk of MAS. The mechanisms include the dilution of meconium, thus reducing the inflammatory effects, its mechanics and cushioning the umbilical cord, in order to correct the umbilical cord compressions that lead to fetal acidemia (a predisposing condition for the elimination of meconium in the uterus). However, there is still a need for more studies on the subject to prove the benefits of the technique, since in the end the 
study does not recommend the performance of amnion fusion for the prevention of MAS [27]. The studies show the importance of a trained and coordinated team for a quick response in this situation, with the aim of reducing neonatal morbidity and mortality, since frailty perinatal care can contribute to increase these rates. In addition, greater investments in health are needed, as they vary according to the distribution of wealth in each region, with greater investment in the main centers industrial activity and in the capitals [28].

After initial care in the delivery room, the newborn may need strict monitoring, which will include monitoring of capillary blood glucose and cardiorespiratory, nutrition, use of other drugs to prevent sepsis as well as ventilatory assistance [29]. Furthermore Nona et al. [30] identified a longer time of mechanical ventilation in newborns who were admitted outside and were transferred when compared with newborns who were born in the maternity ward (median time of ten days versus 4.5 days in newborns in maternity), but not statistically significant, and longer oxygen supplementation time also for those admitted from outside (median time of 15 versus 45 days), with a value of $p=0.0063$, considered statistically significant. Such information emphasizes the importance of monitoring the progress of labor and delivery, fetal and neonatal conditions at birth, so that the team can carry out the required care according to the newborn's needs [29].

Like any type of study, the integrative literature review has advantages and limitations of the method itself, and care should be taken regarding the conclusions related to the findings. However, it's necessary to highlight the potential of the integrative literature review, since it is valid among experts in the review area. In addition, the study presented as a limitation especially when the number of the studies is reduce, however this limitation can be minimized through discussion and consensus among reviewers.

\section{Conclusions}

The main concern in relation to meconium amniotic fluid is related to the elimination and consequent aspiration by the fetus, which may result in MAS, with high morbidity and mortality rates for newborns. Studies show a problem experienced by health professionals in the prevention of MAS, since in the routine there are divergences in the standardization in the different services in relation to the assistance provided to the newborn with the elimination of meconium amniotic fluid.

Therefore, it is concluded that more studies are needed that address the theme, so that early and qualified intervention in conjunction with systematized actions by different health professionals can reduce neonatal morbidity and mortality rates.

\section{Conflicts of Interest}

The authors declare no conflicts of interest regarding the publication of this paper. 


\section{References}

[1] Kwong, T.C. and Ryan, R.M. (1997) Detection of Intrauterine Illicit Drug Exposure by Newborn Drug Testings. National Academy of Clinical Biochemistry. Clinical Chemistry, 43, 235-242. https://doi.org/10.1093/clinchem/43.1.235

[2] Dargaville, P.A. and Copnell, B. (2006) The Epidemiology of Meconium Aspiration Syndrome: Incidence, Risk Factors, Therapies and Outcome. Pediatrics, 117, 1712-1721. https://doi.org/10.1542/peds.2005-2215

[3] Santos Filho, O.O., Sollero, C.P.A. and Silva, J.C.G. (2013) Estudo de alguns fatores de risco para a presença de mecônio no líquido amniótico. Journal of Medical Sciences, 12, 151-161.

[4] Mendonça, S.D., et al. (2015) Síndrome da aspiração meconial: Identificando situações de risco obstétricos e neonatais. Journal of Research: Fundamental Care Online, 7, 2910-1918.

[5] Poggi, S.H. and Ghidini, A. (2009) Pathophysiology of Meconium Passage into the Amniotic Fluid. Early Human Development, 85, 607-610.

https://doi.org/10.1016/j.earlhumdev.2009.09.011

[6] Osava, R.H., et al. (2012) Fatores maternos e neonatais associados ao mecônio no líquido amniótico em um centro de parto normal. Revista de Saúde Pública, 46, 1023-1029. https://doi.org/10.1590/S0034-89102013005000005

[7] Brasil. Ministério da Saúde (2011) Secretaria de Atenção à Saúde Departamento de Ações Programáticas e Estratégicas. Atenção à saúde do recém-nascido: Guia para os profissionais de saúde/Ministério da Saúde, Brasília.

[8] Colvero, M.O. and Garcia, P.C.R. (2006) Novas opções terapêuticas na síndrome de aspiração de mecônio, pós-graduação em medicina. Revista Brasileira de Saúde Materno Infantil, 6, 367-374. https://doi.org/10.1590/S1519-38292006000400002

[9] Van Ierland, Y. and Beaufort, A.J. (2009) Why Does Meconium Cause Meconium Aspiration Syndrome? Current Concepts of Meconium Aspiration Syndrome Pathophysiology. Early Human Development, 85, 617-620.

https://doi.org/10.1016/j.earlhumdev.2009.09.009

[10] Louis, D., et al. (2014) Predictors of Mortality in Neonates with Meconium Aspiration Syndrome. Indian Pediatrics, 51, 637-640.

https://doi.org/10.1007/s13312-014-0466-0

[11] Meritano, J., et al. (2010) Síndrome de dificultad respiratoria asociado a líquido amniótico meconial en recién nacidos de término y postérmino: Incidencia, factores de riesgos y morbimortalidad. Revista del Hospital Materno Infantil Ramón Sarda, 20, 113-119.

[12] Whittemore, R. and Knafl, K. (2005) The Integrative Review: Updated Methodology. Journal of Advanced Nursing, 52, 546-553. https://doi.org/10.1111/j.1365-2648.2005.03621.x

[13] De Sousa, et al. (2011) The Nursing Scientific Production about the Clinic: An Integrative Review. A Revista da Escola de Enfermagem da USP, 45, 494-500. https://doi.org/10.1590/S0080-62342011000200027

[14] Hofmeyr, G.J. and Xu, H. (2010) Amnioinfusion for Meconium-Stained Liquor in Labour. Cochrane Database of Systematic Reviews, No. 1, CD000014. https://doi.org/10.1002/14651858.CD000014.pub3

[15] Lin, H.C., et al. (2008) Meconium Aspiration Syndrome: Experiences in Taiwan. Journal of Perinatology, 28, 43-48. https://doi.org/10.1038/jp.2008.157

[16] Walsh, M.C. and Faranoff, J.M. (2007) Meconium Stained Fluid: Approach to the 
Mother and the Baby. Clinics in Perinatology, 34, 653-665. https://doi.org/10.1016/j.clp.2007.10.005

[17] Hofer, N., et al. (2013) Meconium Aspiration Syndrome: A 21-Years' Experience from a Tertiary Care Center and Analysis of Risk Factors for Predicting Disease Severity. Klinische Pädiatrie, 225, 383-388. https://doi.org/10.1055/s-0033-1361105

[18] Lin, H.C., et al. (2004) Risk Factors of Mortality in Meconium Aspiration Syndrome. Acta Paediatrica, 45, 30-34.

[19] Gregory, G.A., et al. (1974) Meconium Aspiration in Infants Prospective Study. The Journal of Pediatrics, 85, 848-852. https://doi.org/10.1016/S0022-3476(74)80358-6

[20] Keenan, W.J. (2004) Recommendations for Management of the Chile Born through Meconium-Stained Amniotic Fluid. Pediatrics, 113, 133-134. https://doi.org/10.1542/peds.113.1.133

[21] Vain, N.E. (2004) Oropharyngeal and Nasopharyngeal Suctioning of Meconium-Stained Neonates before Delivery of Their Shoulders: Multicentre, Randomised Controlled Trial. The Lancet, 364, 597-602. https://doi.org/10.1016/S0140-6736(04)16852-9

[22] Halliday, H.L. and Sweet, D. (2007) Intubación endotraqueal para la prevención de morbimortalidad en $\mathrm{RN}$ a término, vigorosos y teñidos de meconio (Revisión Cochrane traducida). En: La Biblioteca Cochrane Plus, v. 4.

[23] American Heart Association, American Academy of Pediatrics (2005) Texto de Reanimación Neonatal. 5ta Edición, Elk Grove Village.

[24] Diniz, E.M.A. and Ceccon, M.E.J.R. (2000) Síndrome de aspiração meconial. Pediatria Moderna, 36, 42-44.

[25] Ahumada, C.A. and Goldmith, J.P. (1996) Continuous Distending Pressure. In: Goldsmith, J.P. and Karotkin, E.H., Eds., Assisted Ventilation of the Neonate, 3rd Edition, WB Saunders, Philadelphia, 151-165.

[26] Steven, M., Donn, S.M. and Dalton, J. (2009) Surfactant Replacement Therapy in the Neonate beyond Respiratory Distress Syndrome. Respiratory Care, 54, 1203-1208.

[27] Fraser, W.D., et al. (2005) Amnioinfusion for the Prevention of the Meconium Aspiration Syndrome. The New England Journal of Medicine, 353, 909-917. https://doi.org/10.1056/NEJMoa050223

[28] Daripa, M., et al. (2013) Asfixia perinatal associada à mortalidade neonatal precoce: Estudo populacional dos óbitos evitáveis. Revista Paulista de Pediatria, 31, 37-45. http://www.scielo.br/pdf/rpp/v31n1/07.pdf https://doi.org/10.1590/S0103-05822013000100007

[29] Bhutani, V.K. (2008) Developing a Systems Approach to Prevent Meconium Aspiration Syndrome: Lessons Learned from Multinational Studies. Journal of Perinatology, 28, 30-35. https://doi.org/10.1038/jp.2008.159

[30] Nona, J., et al. (2009) Ventilação de alta frequência na síndrome de aspiração meconial. Einstein, 7, 201-205. 